\title{
NORMAL LIVING: ARSITEKTUR BERPERAN SEBAGAI PENGUBAH STIGMA BURUK \& DISKRIMINASI ATAS KAUM DIFABEL
}

\author{
Jihan Nurmaulida ${ }^{1)}$, Suryono Herlambang ${ }^{2)}$ \\ 1)Program Studi S1 Arsitektur, Fakultas Teknik, Universitas Tarumanagara,jihan.315170208@stu.untar.ac.id \\ 2) Program Studi S1 PWK, Fakultas Teknik, Universitas Tarumanagara, suryonoh@ft.untar.ac.id
}

Masuk: 03-07-2021, revisi: 15-08-2021, diterima untuk diterbitkan: 23-10-2021

\begin{abstract}
Abstrak
Berlatar belakangi isu Difabel yang kian berujung menjadi pengangguran lalu hidup miskin karena terjadinya diskriminasi terhadap mereka, atau tidak mendapatnya hak dan kesempatan yang sama seperti kalangan masyarakat lainnya. Yang bahkan bisa dilihat dari sisi arsitektur pun, sebagian besar sebuah ruang berisi penghalang fisik yang secara tidak sengaja menciptakan "desain apartheid", di mana penyandang disabilitas dikecualikan dari area karena tata letak ruang yang tidak dapat diakses. Normal Living merupakan sebuah proyek berlokasi di Sunter Agung dimana para Tuna Daksa berkusi roda diberi pekerjaan pada industri kebaya, gaun dan jas, yang nanti nya akan mereka pamerkan melalui wheelchair dance \& fashion runway. Mereka diberi penghidupan layak yaitu diberi akomodasi tempat tinggal dengan adanya Farming sebagai Suplai Makanan mereka, dan tentu sebagai tempat mereka mendapatkan moral support lewat hidup berkomunitas. Normal Living ini bertujuan untuk mengubah stigma buruk yang beredar di masyarakat kalau mereka tidak bisa melakukan apa-apa, mengubah dari internal diri mereka sendiri untuk membuat mereka merasa percaya diri bahwa mereka normal, karena bahwasanya, pelabelan normal dan tidak normal hanyalah sebuah persepsi. Sehingga secara implisit, Normal Living bertujuan sebagai produk arsitektural yang berkampanye akan kesetaraan. Melakukan aktivitas yang dianggap mereka tidak bisa lakukan lewat entertainment - menari dan menjadi fashionable. Untuk mencapai tujuan dari proyek ini Metode Perancangan yang digunakan pada Normal Living ini yang pertama yaitu Kenyamanan Mereka Para pengguna kursi roda adalah prioritas Utama, lalu persepsi spasial untuk membentuk persepsi kepada para pengguna bangunan, yang kedua berbentuk program kolektif dan ketiga, menegaskanaspek transpansi pada material untuk pembuktian.
\end{abstract}

Kata kunci: Difabel; Tempat Layak; Persepsi Spasial

\begin{abstract}
Built based on the keep-increasing issues of disabilities for those who live in the event of poverty due to discriminations, or for not having the same rights and/or opportunities as others on the community. Though, also reflected from the point of view of architectural that most of the spaces contain physical barriers, which Un purposely happened to create "design apartheid", where disabilities treated as ones who are 'excluded' in the area caused by the inaccessible layout in the space. Normal Living is a project, built and located in Sunter Agung, where disabilities, specifically who are in wheelchairs, are given the opportunities of working in industry such as kebayas, dresses, and suits,. The product's later will be shown and presented through Wheelchair Dance and Fashion Runway. In daily life they are also given a quite decent life support, such as, a proper living accommodation with the existence of urban farming activities to provide their daily need of food. For moral support, they could do their social-life in the provided community. Normal Living is built with purpose to remove bad stigma of the inabilities of disabilities, which been overly years becoming what the public belief. Not only to remove it from public, but more importantly to remove it from the disabilities themselves. In order to reach it, Normal Living is up to create self confident in each of the disabilities. Therefore we can actually agree that between normal and abnormal are only about perceptions. Normal Living is an architectural projects that implied with Equality campaign, doing such activities (which were used to be considered as the inabilities of disabilities) through entertainment, dancing and fashion. In order to reach the described-above purpose, firstly Normal Living uses the planning method to put the comforts of disabilities as its primer priority and spatial perception to build perception for building users. The second one is to create collective programs, followed by the third which is to emphasizethe transparency aspects during the material of proof.
\end{abstract}

Keywords: Disabilities; Decent Living Places; Spatial Perception 


\section{PENDAHULUAN}

\section{Latar Belakang}

Manusia yang dikaruniai atribut fisik dengan fungsi utuh, terbiasa berfungsi dalam sebuah tautan rutinitas dan kepentingan. Bekerja-beristirahat-menikmati hasil-menabung kelak demi masa depannya. Memiliki lapangan pekerjaan, terlindung dari pengangguran, dan memperoleh kehidupan yang layak merupakan hak yang tidak dapat dicabut dari seseorang sebagai martabat manusia atas kemerdekaan.

Tunadaksa sebagai individu yang memiliki cacat fisik, mereka yang memiiki anggota tubuh tidak sempurna, berbeda dengan orang lain pada umumnya, tentunya mereka memiliki situasi yang lebih kompleks untuk memperolehnya. Bagi mereka, usaha dan bantuan yang 'lebih' dibutuhkan agar dapat memperoleh hak tersebut. Biaya pengobatan, transportasi, mobilitas dan jasa bantuan melakukan aktivitas sehari-sehari bukanlah sebuah hal yang mudah untuk diperoleh. Baik yang kaya maupun yang tidak berkecukupan sekalipun. Keberadaannya penyandang disabilitas dalam sebuah keluarga menjadi pemicu ibu untuk berhenti bekerja. Apalagi jika tidak adanya sosok ayah atau peran pencari nafkah. Ujung-ujungnya mereka bisa membawa jatuh keluarganya ke jurang kemiskinan. Dari sini dapat terbentuklah sebuah lingkaran 'setan' siklus kemiskinan-difabel karena masyarakat miskin sangat rentan melahirkan disabilitas. Ibu hamil yang berada di lingkungan tak sehat \& kekurangan nutrisi cenderung melahirkan bayi dengan berat badan rendah yang rentan mengalami disabilitas (Rof'ah, 2014)

Sehingga untuk menyambung hidupnya, setidaknya para tuna daksa harus hidup mandiri secara finansial. Namun kenyataannya, menurut Harry Hikmat, angka pengangguran penyandang disabilitas terbilang tinggi di Jakarta, dalam diskusi daring Potensi Anak Muda dengan disabilitas memasuki dunia kerja di Jakarta.

Bukan hanya karena merasakan diskriminasi sosial \& rendahnya pendidikan dan pelatihan yang menyebabkan peluang \& keinginan para tunadaksa untuk memiliki pekerjaan menjadi kecil. Tetapi juga, salah satunya bantuan personal dan teknis yang tidak memadai. (Dhungana, 2006 dan Kiani, 2009). Dari perpektif spasial, jarang sekali atau bahkan sekalipun tidak ada sebuah dukungan nyata agar mereka dapat merasa mudah dalam mengerjakan pekerjaan Tidak adanya kesetaraan. Profesor perencanaan kota, Rob Imrie menyimpulkan bahwa sebagian besar sebuah ruang berisi penghalang fisik yang secara tidak sengaja menciptakan "desain apartheid", dimana individu penyandang disabilitas dikecualikan dari area karena tata letak ruang yang tidak dapat diakses. Sehingga arsitek juga dinilai berperan penting untuk berpartisipasi dalam menemukan solusi untuk masalah ini.

\section{Batasan}

Tunadaksa yang dimaksud adalah Wheelchair-bound disabled, kelompok kategori ini, memiliki keterbatasan untuk mobilisasi dari satu tempat ke tempat lain. Maka dari itu mereka dipastikan harus menggunakan alat bantu kursi roda untuk melakukan kehidupan sehari-hari.

\section{Rumusan Permasalahan}

1. Bagaimana arsitektur dapat mewadahi para tunadaksa agar mendapatkan hak yang setara dengan masyarakat pada umumnya?

2. Bagaimana arsitektur dapat menghilangkan diskriminasi terhadap para penyandang disabilitas?

3. Bagaimana arsitektur dapat memberi lingkungan yang aman, ramah dan suportif bagi mereka para tunadaksa? 


\section{Tujuan}

Tujuan penelitian ini adalah untuk mencoba menciptakan wadah arsitektur bagi para tunadaksa agar dapat memiliki pekerjaan, terlindung dari pengangguran, memperoleh kehidupan yang layak dan juga menjadi wadah untuk meningkatan kesadaran masyarakat dan para difabel itu sendiri bahwa mereka setara dan tidak ada bedanya dengan mereka-mereka yang non-difabel (menekankan kesetaraan) Sehingga memenuhi lingkungan yang aman, ramah, suportif dan dapat membantu mereka.

\section{KAJIAN LITERATUR}

Inclusion By Design (Cowan, 1995)

Kualitas bangunan dan ruang memiliki pengaruh kuat pada kualitas hidup seseorang. Keputusan tentang desain, perencanaan dan pengelolaan tempat dapat meningkatkan atau membatasi rasa belonging seseorang terhadap sebuah tempat. Hal ini bisa menambah atau mengurangi perasaan aman, meregangkan atau membatasi batas, mempromosikan atau mengurangi mobilitas, dan meningkatkan atau merusak kesehatan. Dapat menghapus nyata dan imajiner hambatan antara masyarakat pengertian dan kemurahan hati. Meskipun aksesibilitas telah meningkat selama dekade terakhir, dan kebijakan perancangan telah bergeser, dengan investasi menyediakan baru fasilitas untuk komunitas yang pernah dikecualikan, faktanya mereka tetap miskin dan kurang beruntung jauh lebih mungkin untuk hidup dalam kemiskinan lingkungan yang berkualitas. Sosial, budaya dan kesenjangan ekonomi masih secara harfiah dibangun ke tempat-tempat baru, dan perencana dan desainer perlu memeriksa lebih dekat dampak dari keputusan mereka. Setiap bangunan dan situs menjadi peluang pedagogis untuk eksplorasi air, energi, makanan, material, perairan, dan biodiversitas.

\section{For me or not for me? Why people experience the same place differently}

Pengalaman spasial orang-orang di suatu tempat dan lingkungan berbeda berdasarkan siapa mereka - sosial, budaya dan latar belakang ekonomi. Penuh keragaman pengalaman ini perlu dipertimbangkan jika semua pengguna ingin nyaman dan merasa bahwa tertentu ruang atau tempat adalah milik mereka.

\section{Inclusive Design}

1) Acces with Dignity - mencapai, dan ke tempat-tempat, dan menggunakan martabat. Ini tentang akses fisik ke tempat dan layanan, termasuk akses ke teknologi tepat guna

2) Treatment with Respect - bagaimana orang-orang ditangani, diajak bicara dan dirawat; apakah mereka kebutuhan dipertimbangkan dan apakah mereka dihormati dan disambut.

3) Relevant Services - lakukan tempat memenuhi kebutuhan khusus orang? Apakah mereka dirancang dengan pengguna dipikiran? Apakah mereka memberi orangmerasa bahwa mereka memiliki hak untuk berada di sana? 


\section{Aksesibilitas}

Negara semestinya mengakui pentingnya aksesibilitas dalam proses terciptanyan kesamaan kesempatan dalam semua aspek kehidupan dalam kegiatan bermasyarakat bagi difabel dari semua jenis kecacatan yang ada. Hak dan kewajiban difabel semestinya terpenuhi sama dengan hak dan kewajiban dari non difabel.

Menurut (Hapsari, 2011)aksesbilitas terbagi atas dua macam yaitu:

a. Aksesbilitas fisik yaitu berupa aksesibilitas pada bangunan umum; aksesibilitas pada jalan umum; aksesibilitas pada pertamanan dan pemakaman umum; aksesibilitas pada angkutan umum.

b. Aksesbilitas non fisik yaitu berupa pendidikan daun ketenagakerjaan. Semua difabel memiliki kesempatan yang sama dalam memperoleh pendidikan dan pekerjaan.

Aksesibilitas fisik dan non fisik bagaikan dua sisi mata uang yang tidak bisa dipisah-pisahkan karena jika satu sisi mata uang itu tidak bergambar maka uang tersebut tidak akan dapat di belanjakan. Untuk itu memang kedua hal ini harus bersama-sama diterapkan jika kita ingin memberdayakan difabel.

\section{Normal}

"Human beings are not stereotypes. We are not defined by everyday assumptions, about what it is to be disabled/abled, old/young, female/male, black/ white or fat/thin. But we do live our relationships to these (and other) stereotypes, and to our own and other people's commonsense beliefs about how the world works, what is normal behaviour, what is an 'unsatisfactory' life and so on." (Boys, 2014)

Pada bukunya Jos Boys yang berjudul Doing Disability Differently , dia memaparkan bahwa manusia itu bukanlah sebuah stereotype. Manusia tidak didefinisikan dari asumsi sehari-sehari. Disini menegaskan bahwa semua manusia itu normal. Berbeda-beda dengan yang biasanya bukan berarti abnormal.

\section{Membuat Difabel merasa Normal}

membuat suatu produk arsitektural yang mempunyai fokus utama pada difabel, membuat merasa mereka diterima karena mereka berada di dalam dunia yang sama. Melihat orang lain melakukan hal yang sama, membuat mereka merasa lebih dominan atau memiliki power dibanding yang non-difabel adalah salah satu alternatif untuk membuat mereka merasa normal.

\section{METODE}

Untuk mencapai visi dan misi keberhasilan Nor"mal Living, maka ada beberapa point point penting yang perlu di perhatikan untuk dijadikan strategi.

\section{Tahap Pengumpulan Data:}

Studi Literatur

- Sebagai dasar teoritis untuk dasar konsep pemikiran

- Mengetahui dasar yang terkait untuk merancang desain

Studi Preseden

- Sebagai pembanding proyek

- Mengerti Standart yang dipakai proyek yang dijadikan sebagai preseden

Pengamatan lingkungan sekitar kawasan

- Lokasi: Kawasan Sunter Agung

- Metode Pengamatan: a) Pengamatan dari google maps, b) analisa kawasan 


\section{Metode Desain}

- Kenyamanan Pengguna Kursi Roda Prioritas Utama

Penyediaan aksesibilitas berdasarkan asas kemudahan, kegunaan, keselamatan, dan kemandirian untuk mewujudkan peningkatan kesejahteraan sosial dan penghidupan bagi para Tuna Daksa pengguna Kursi Roda yang akan didesain berdasarkan Keputusan Menteri Pekerjaan Umum Republik Indonesia No: 468/KPTS/1998 Tentang Persyaratan Teknis Aksesbilitas Pada Bangunan Umum dan Lingkungan.

- Persepsi Spasial
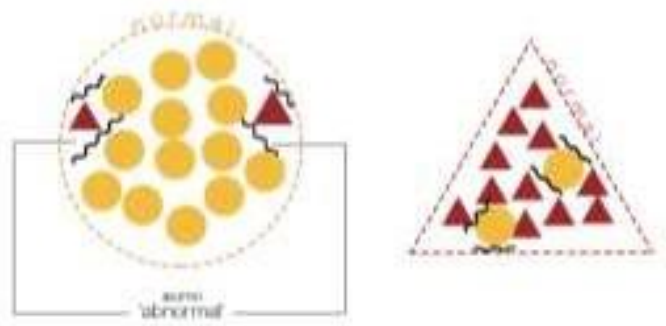

Gambar 1. Diagram asumsi abnormal Sumber: Penulis, 2021

Zumthor dalam buku Zumthor Atmospheres (2010) menggambarkan pendekatan ini berdasarkan 'perasaan' - pada 'emosional daripada respon linier, yaitu, intuitif dan impresionistik daripada intelektual. Zumthor bertujuan untuk mendeskripsikan cara yang digunakan ruang yang dirancang dapat meningkatkan sensasi langsung yang kita dapatkan ketika kita memasuki suatu ruang. Yang mana akan didesain dengan Ratio Aksesibilitas Tuna Daksa pada bangunan akan lebih ditonjolkan sehingga tuna daksa merasa lebih merasa percaya diri karena merasa diprioritaskan dan seperti merasa pada dunia mereka

\section{- Kolektif}

Dalam kehidupan sosial sehari-hari, acap kali seseorang terlalu cepat menilai negatif orang atau kelompok lain yang berbeda dengan dirinya tanpa dasar atau bukti yang meyakinkan. Mendesain ruang pertemuan banyak orang - Keberagaman dapat menjadi faktor yang berkontribusi terhadap kemampuan untuk mengatasi prasangka dengan baik. Menghilangkan barrier \& diskriminasi terhadap penyandang disabilitas.

\section{- Transparansi}

Aktivitas Para Tuna Daksa khususnya Wheelchair dance \& Fashion Show akan di expose menggunakan material transaparan pada bangunan. Hal ini bertujuan untuk seperti tindakan kampanye untuk membuktikan kepada masyarakat atas stigma-stigma yang ada.

\section{Hasil Perancangan}

Hasil dari Percangan berupa sebagai produk arsitektural yang berkampanye akan kesetaraan bagi para disabilitas khususnya tuna daksa. 


\section{DISKUSI DAN HASIL}

\section{Pemilihan \& Kriteria Lokasi}

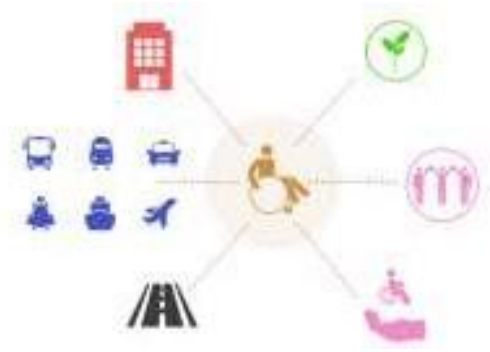

Gambar 2. Kriteria Tapak pengguna kursi roda Sumber: Penulis, 2021

Dalam The Future of Disability in America: Menjadi seorang tunadaksa (difabel) yang rentan akan kemiskinan karena banyaknya biaya yang dikeluarkan. Sehingga kriteria tapak harus memikirkan untuk mengurangi biaya untuk keluarga:

1. Mengurangi biaya pengobatan kesehatan: Lingkungan Sehat menerapkan strategi low carbon dalam pemakaian energi. (World Health Organization)

2. Dekat dengan moda transportasi, untuk mobilitas

3. Dekat dengan Rumah Sakit agar mudah jika ada kecelakaan.

4. Area yang rata, tidak ada retakan, penumpukan kotoran atau penghalang lainnya.

5. Mengurangi kesenjangan di antara para penyandang disabilitas:

a. Dekat dengan ruang rekreasi publik yang inklusif

b. Dekat dengan tempat komunitas tuna daksa.

\section{Tapak}

Lokasi perancangan dipilih atas dasar kontekstualitas ruang yang mampu menjawa rumusan masalah serta visi dari proyek ini. Tapak dipilih juga sesuai dengan kriteria pemilihan lokasi yang cocok untuk isu yang ada, berlokasi Jl. Danau Sunter Utara, Sunter Agung, Tj. Priok, Kota Jkt Utara, Sub Zona Perkantoran Perdagangan \& Jasa. Tapak dikelilingi banyak industri jasa dan perumahan. Dan juga disebelah timur tapak terdapat Pasar Sunter Jaya.
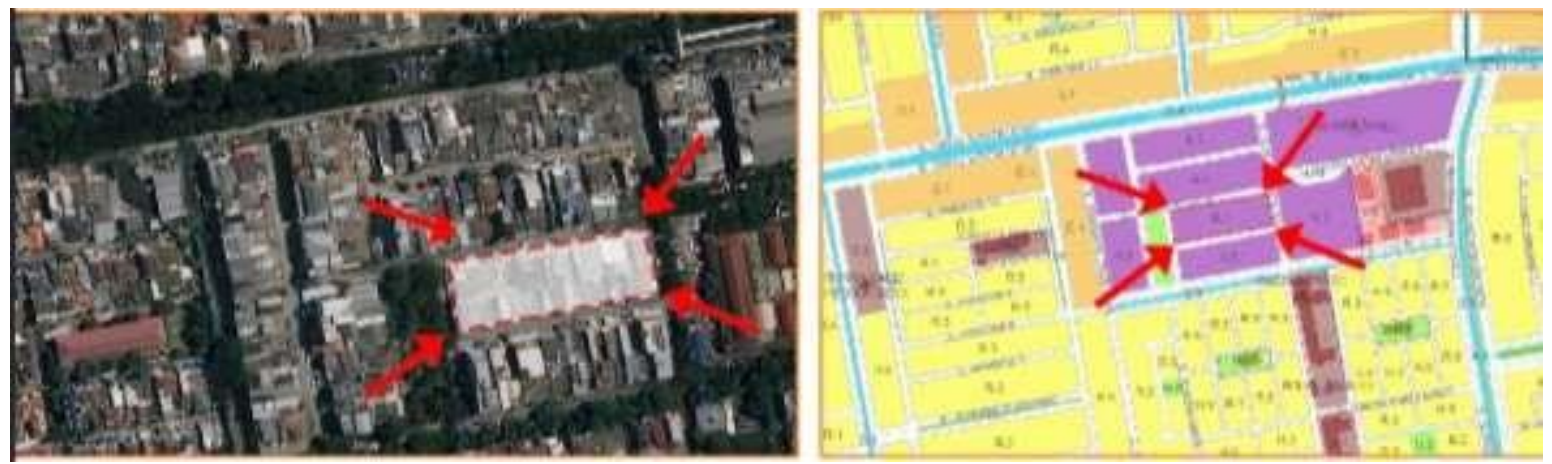

Gambar 3. Lokasi dan Zonasi Tapak

Sumber: Penulis, 2021 


\section{Kriteria}

Tidak Rawan Banjir

Dekat dengan moda transportasi

Dekat dengan Rumah Sakit

Dekat dengan tempat Rekreasi

Area yang rata, tidak ada retakan, penghalang

Dekat dengan komunitas tuna daksa

\section{Eksisting}

Di depan terdapat Saluran, terdapat kemungkinan rawan banjir

Halte Transjakarta Sunter dalam jarak +$200 \mathrm{~m}$

Royal Progress Hospital berada dalam radius +-500 m dalam tapak

Waduk Sunter Utara, Stadion \& Taman BMW dalam jarak $1.44 \mathrm{~km}$

Sunter Shopping Mall +- $50 \mathrm{~m}$

Trotoar rapih \& permukaan rata hingga +$1.5 \mathrm{~km}$ dari tapak

Adanya komunitas tuna terdekat dengan tapak

\section{Konsep}

Konsep Normal Living adalah berusaha untuk mengurangi dampak dari hasil siklus difabelkemiskinan yang bertindak dengan cara bangunan sebagai Kampanye kesetaraan \& hak bagi para pengguna kursi roda. Normal Living ingin membuat para Tuna Daksa merasa normal. Karena pada dasarnya sebuah ke'tidak-normal'an hanyalah sebuah persepsi.

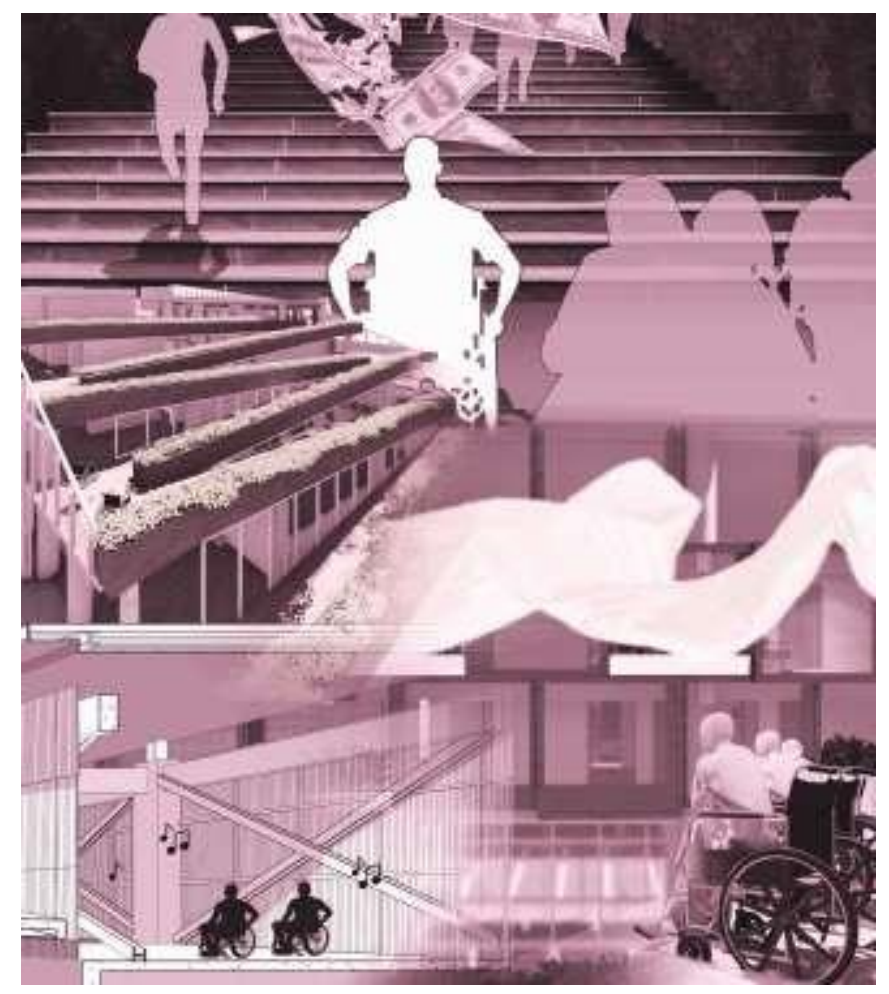

Gambar 4. Illustrasi Normal Living

Sumber: Penulis, 2021 


\section{Parameter Normal Living sebagai Beyond Ecology}

Normal Living memiliki parameter, yang pertama mengubah Stigma eksternal yang beredar di masyarakat kalau mereka tidak bisa apa-apa, yang kedua, mengubah internal diri mereka untuk membuat mereka merasa percaya diri bahwa mereka sebenarnya juga representasi dari pelabelan kata normal. Setelah itu, memberi mereka support berbasis komunitas dan penghidupan yang layak berupa bangunan yang sangat aksesibel.

\section{Analisis Latar Belakang menuju Program}

Program ditempatkan berdasarkan dari hasil analisis beyond ecology atas isu diskriminasi difabel dan sesuai strategi konsep yang ingin diwujudkan

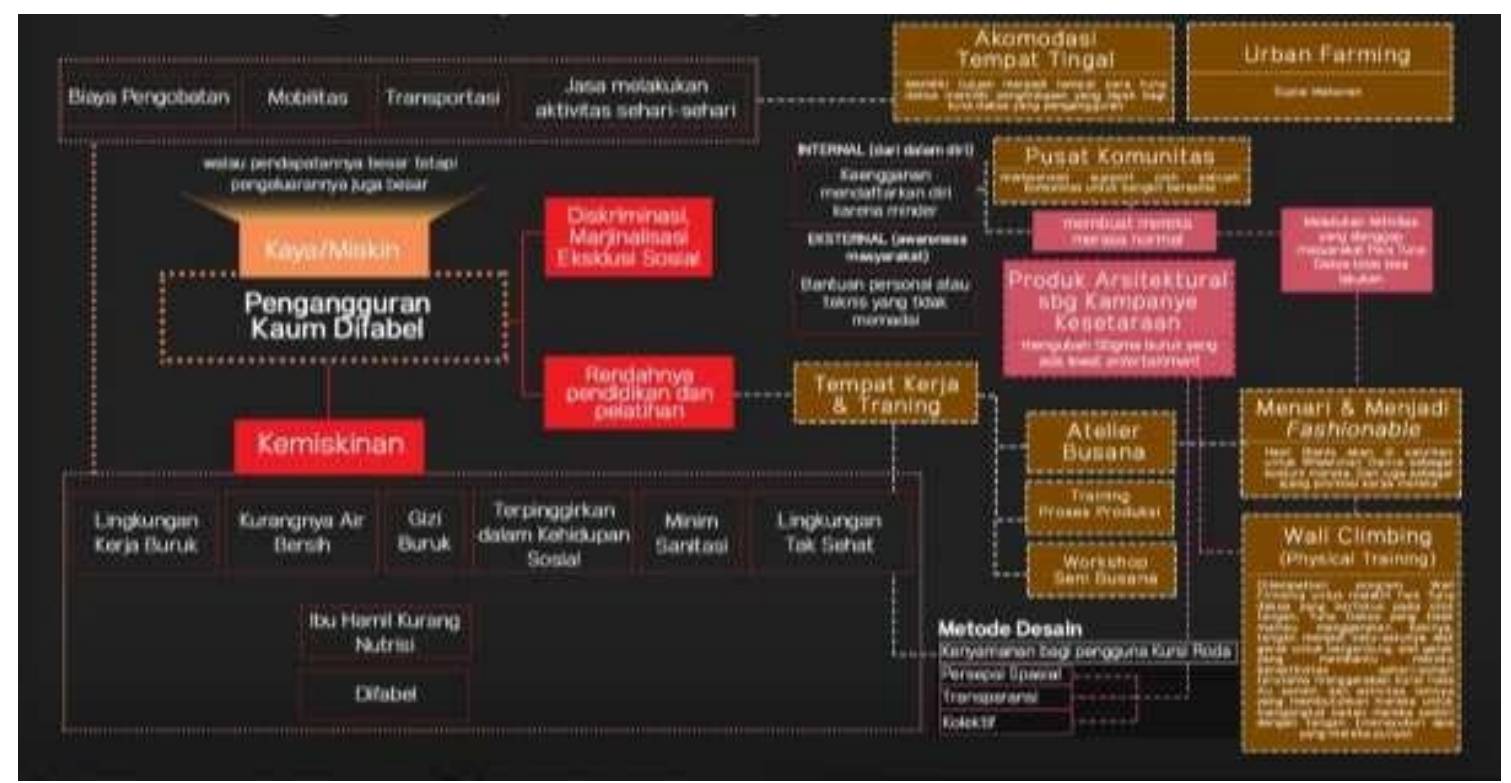

Gambar 5. Analisis Program Normal Living Sumber: Penulis, 2021

\section{Program Normal Living}

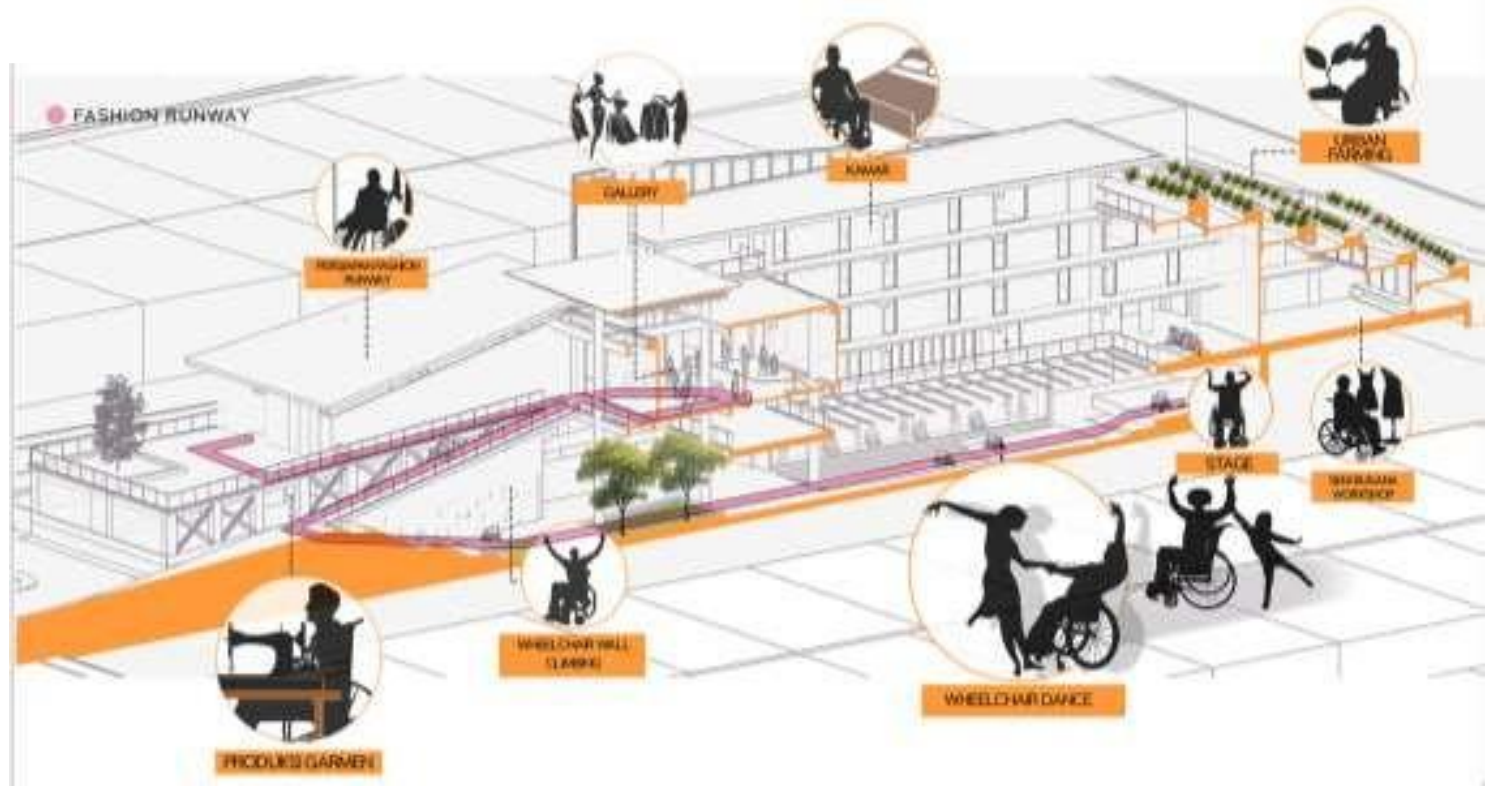

Gambar 6. Potongan Aksonometri Normal Living

Sumber: Penulis, 2021 
a. Atelier Busana Jas, Gaun \& Kebaya

Menjadi Wadah tunadaksa agar dapat memiliki pekerjaan terlindung dari pengangguran dengan menjadi pekerja di pembuatan industri kebaya dan gaun.

b. Akomodasi Tempat Tinggal:

Memiliki tujuan menjadi tempat para tuna daksa memiliki penghidupan yang layak bagi para tuna daksa yang pengagguran.

c. Pusat Komunitas

Menjadi wadah bagi yang aman, ramah, suportif dan dapat membantu mereka dalam mencoba untuk bangkit berbasis komunitas.

d. Farming

Farming ditujukan khusus untuk menjadi suplai makanan mereka. Mereka dapat mengkonsumsi makanan dari kerja keras mereka sendiri.

e. Wheelchair Dance \& Fashion Show

Hasil Bisnis akan disalurkan untuk Wheelchair Dance sebagai kostum mereka. Dan juga sebagai ajang promosi karya mereka.

f. Panjat Tebing (Traning Fisik)

Ditempatkan program Wall Climbing untuk melatih fisik tuna daksa yang berfokus pada otot tangan Tuna Daksa yang tidak mampu menggerakan kakinya. Hal ini dimaksudnkan untuk mereka para tuna daksa mensyukuri apa yang mereka punya, karena Tangan telah menjadi satu-satunya alat gerak yang mereka punya dan alat mereka untuk bergantung untuk melakukan aktivitas tiap harinya.

\section{Pengaplikasian Metode pada Bangunan}

a. Contoh Beberapa Metode Kenyamanan Pengguna Kursi Roda Prioritas Utama yang diterapkan pada bangunan:

Tabel 1. Aplikasi Metode

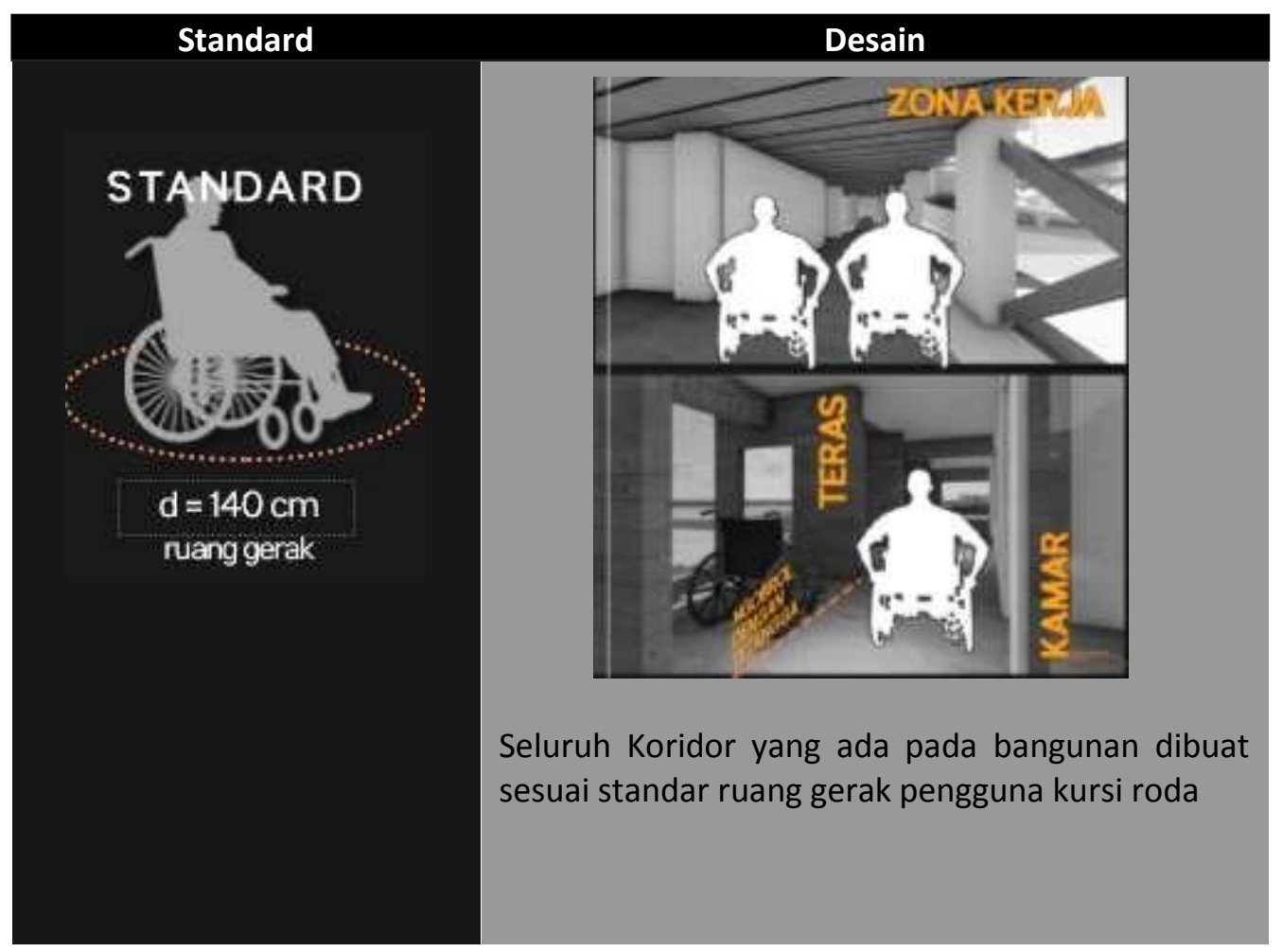




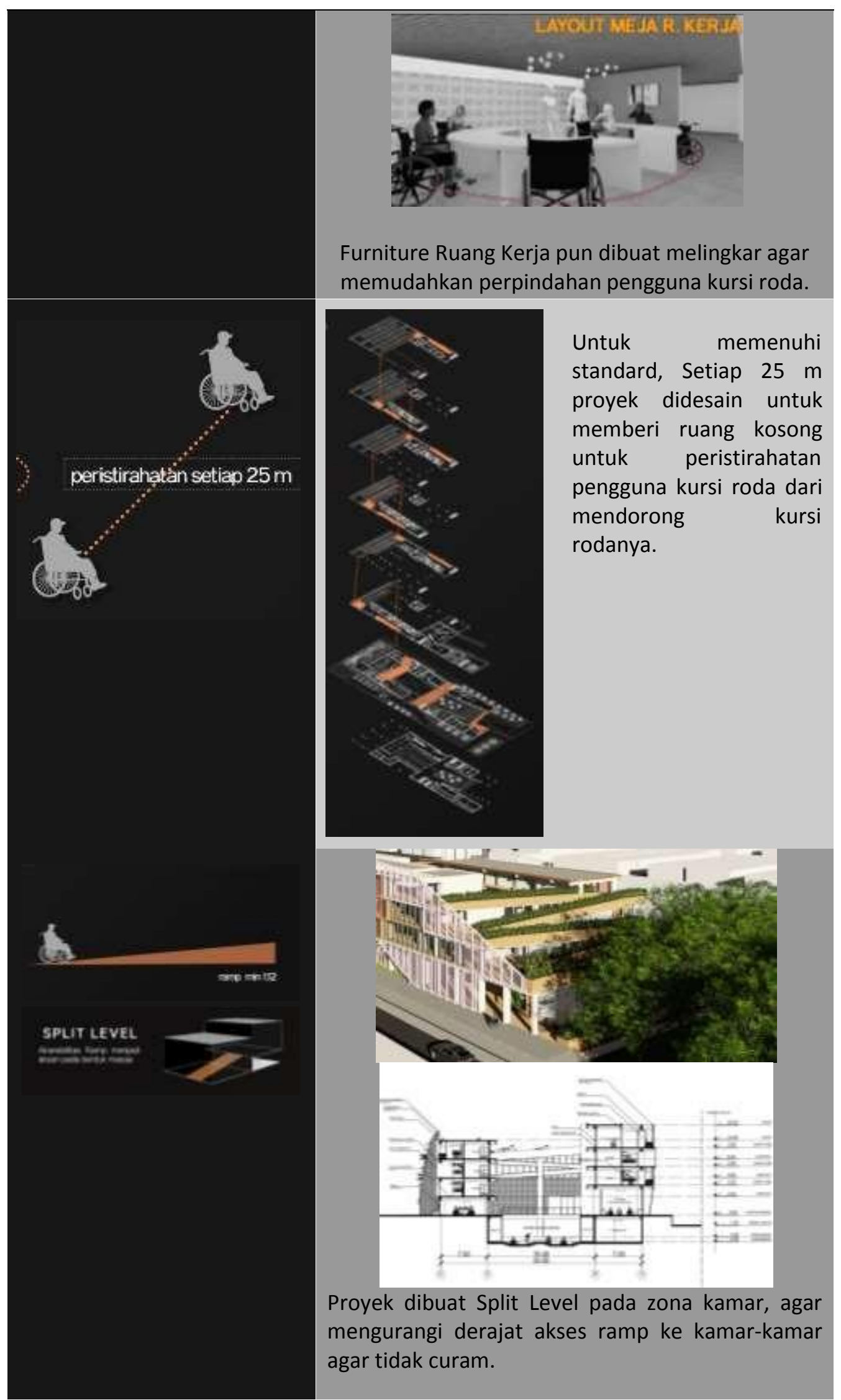

Sumber: Penulis, 2021 
b. Persepsi Spasial
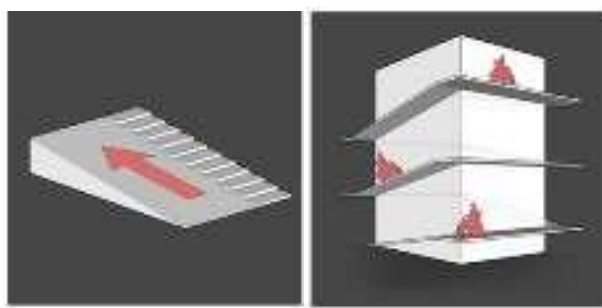

Ratio Aksesibillitas pengguna kursi roda akan lebih ditonjolkan sehingga Tuna daksa merasa percaya diri karena merasa diprioritaskan dan seperti merasa pada dunia mereka. Hal ini diterapkan pada Ramp Entrance Bangunan, Ramp Farming, Ramp menuju Basement.

Gambar 8. Metode rersepsı spasıaı Sumber: Penulis, 2021
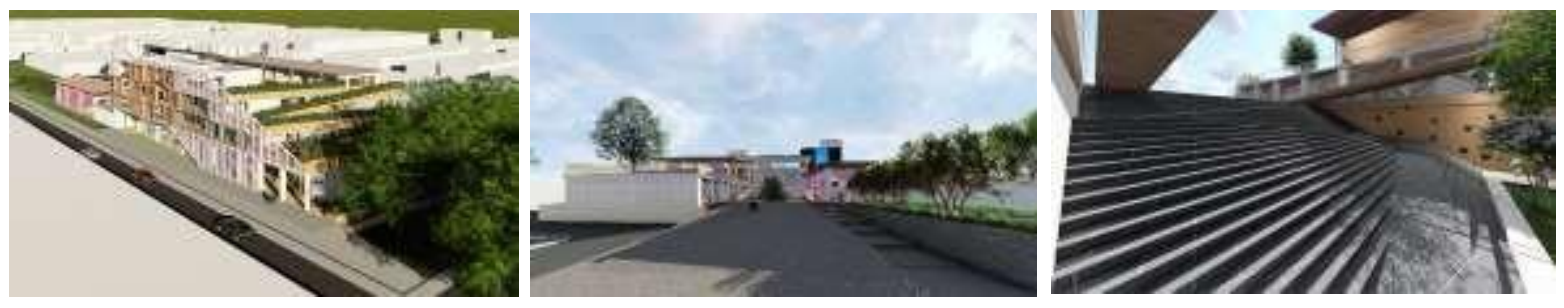

Gambar 9. Ramp-ramp pada bangunan

Sumber: Penulis, 2021

c. Kolektif

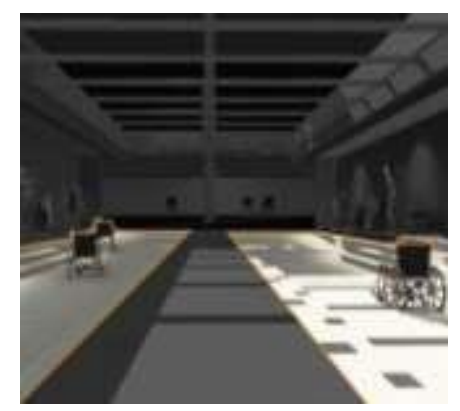

Gambar 10. Area Wheelchair Dance

Sumber: Penulis, 2021

d. Transparansi
Wheelchair Dance sebagai program para tuna daksa dan pengunjung bertemu yaitu tuna daksa dapat mengajak mereka menari. Sehingga terjadi nya interaksi dan komunikasi yang akan memunculkan persepsi baik diantara mereka sehingga menghilangkan barrier prasangka.

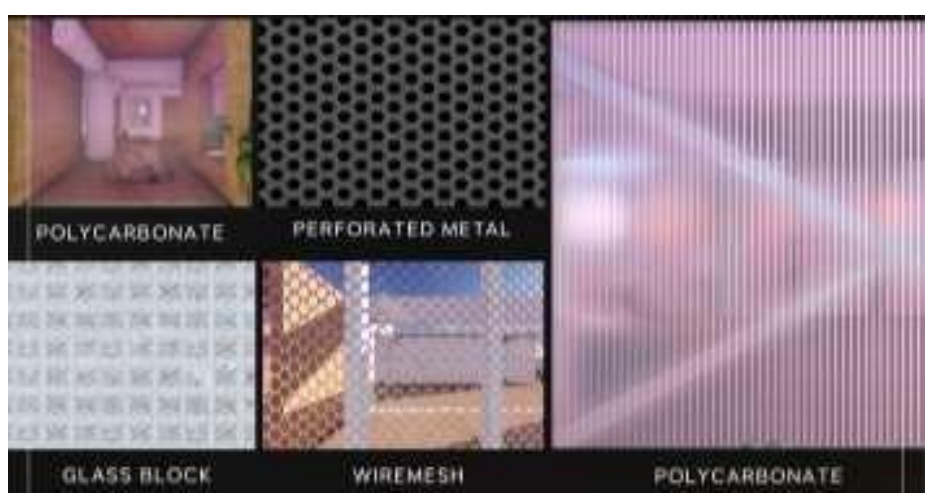

Gambar 11. Material Transparan Normal Living Sumber: Penulis, 2021
Penggunaan Material transparan, seperti polycarbonate, perforated metal, glassblock, dan wiremesh. Penggunaan warna cerah dan colorful pada material juga digunakan karena tuna daksa biasanya cenderung daya penglihatannya berkurang. 


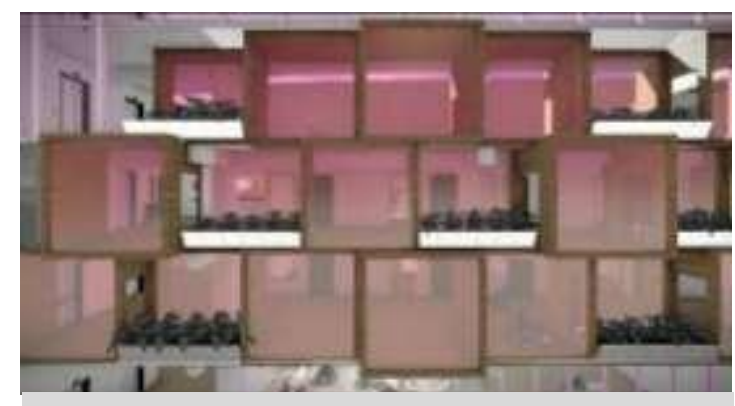

Polycarbonate pada fasad Zona Kamar

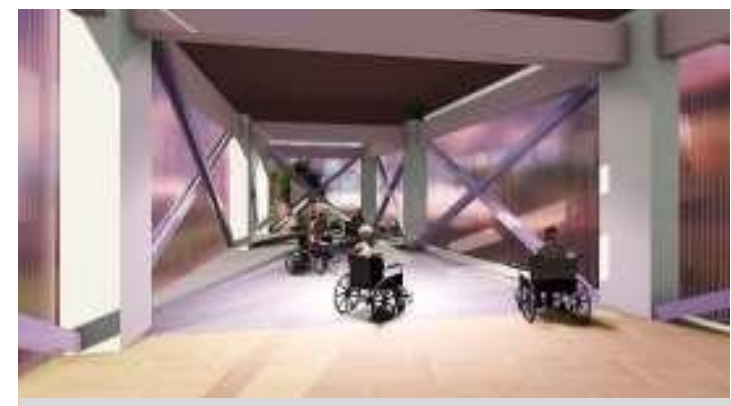

Polycarbonate pada fasad R. Latihan dance

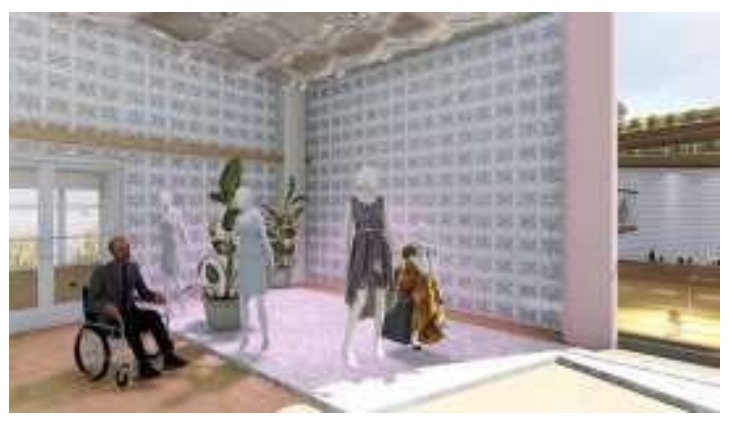

Glass Block pada Fasad Galeri

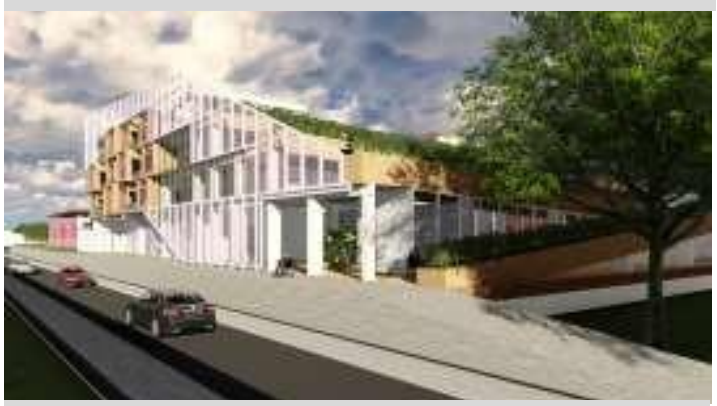

Wiremesh \& perforated metal pada fasad zona kamar

Gambar 12. Penggunaan Material pada ruang-ruang Sumber: Penulis, 2021

\section{KESIMPULAN DAN SARAN}

\section{Kesimpulan}

Untuk menciptakan wadah arsitektur yang inklusif, meningkatan kesadaran masyarakat dan para difabel itu sendiri bahwa mereka setara dan tidak ada bedanya dengan mereka-mereka yang nondifabel - menekankan kesetaraan, membutuhkan perubahan pada desain yang selama ini selalu saja diterapkan yaitu masalah rasio luas akses difabel dibuat lebih kecil yang membuat mereka difabel merasa dikecualikan di dalam bangunan dengan mengubahnya menjadi rasio akses menjadi setara.

Karena alasan bangunan ini dibuat khusus untuk para tuna daksa dan menjadi kampanye arsitektural sehingga desain dibuat keseluruhan dengan akses tuna daksa agar menyadarkan masyarakat bahwa ternyata rasio akses desain harus disesuaikan dengan siapa pengguna bangunan. Pengguna $A$, wadah A. Pengguna B, wadah B. Pengguna $C$, wadah $C$. Yang mana menuju pada pernyataan, bahwa kita hidup di dunia ini dengan $A, B, C, D, E, F$ hingga $Z$ atau lebih (bermacam-macam perbedaan) sehingga semua tempat yang menggabungkan varietas tersebut harus mendesain akses yang setara dan menyesuaikan itu semua. Yaitu, wadah A, B, C, D, E, F hingga Z tadi. Wadah arsitektur yang inklusif.

Lalu, untuk mendukung hal tersebut pada proyek ini, salah satunya dibuatnya program-program penggerak ekonomi rumah tangga mereka yang dapat mengedukasi masyarakat secara implisit, memengaruhi persepi masyarakat, lewat art \& entertainment yang tidak memberikan pembelajaranpembelajaran yang terasa kaku yang kita dapat dari teori manapun. Program memuat aktivitas yang jarang diketahui banyak orang bahwa para difabel dapat melakukan hal tersebut yaitu, menari dan menjadi fashionable yang seharusnya memang normal-normal saja untuk mereka lakukan. Yang mana, aktivitas ini juga memiliki tujuan secara kolektif untuk menghubungkan mereka para tuna daksa dengan pengunjung sehingga meruntuhkan barrier prasangka pada 'kesan pertama' yang umumnya 
menyebabkan terjadinya diskriminasi, hilang karena adanya interaksi antar mereka. Mengenal satu sama lain dengan menari bersama pada wheelchair dance area di ruang terbuka.

Keseluruhan konsep ini juga didukung dengan penggunaan material yang transparan yang mengekspos kegiatan mereka sehingga menjadi semacam pembuktian kepada masyarakat luas.

\section{REFERENSI}

Boys, J. (2014). Doing Disability Differently. New York: Routledge.

Chernichenko, A. (n.d.). UNIVERSAL DESIGN IN URBAN ENVIRONMENT. Retrieved from Future Architecture: https://futurearchitectureplatform.org/projects/eaafe2fe-ec16-40c1-84ce914ca006b64e/

Commission for Architecture and the Built Environment. (2008). Inclusion by design.

Disability and Poverty. (2021, April 23). Retrieved from Wikipedia The Free Encyclopedia: https://en.wikipedia.org/wiki/Disability_and_poverty

Fajri Nursyamsi, E. D. (n.d.). Kerangka Hukum Disabilitas di Indonesia : MENUJU INDONESIA RAMAH DISABILITAS.

Hapsari, G. (2011). Aksesibilitas Difabel dalam Ruang Publik (Studi Deskriptif Kualitatif Mengenai Aksesibilas Difabel Dalam Ruang Publik di Kota Surakarta).

Institute of Medicine of National Academies. (2007). The Future of Disability in America. Washington, D.C.: The National Academies Press .

KEPUTUSAN MENTERI PEKERJAAN UMUM REPUBLIK INDONESIA. (1998). PERSYARATAN TEKNIS AKSESIBILITAS PADA BANGUNAN UMUM DAN LINGKUNGAN. DEPARTEMEN PEKERJAAN UMUM.

Kustiani, R. (2020, September 11). 10 Sebab Pengangguran pada Penyandang Disabilitas Terbilang Tinggi. Retrieved from TEMPO.CO: https://difabel.tempo.co/read/1385107/10-sebabpengangguran-pada-penyandang-disabilitas-terbilang-tinggi

Rof'ah. (2014). Mengurangi Kompleksitas Kemiskinan Difabel. 245.

Zumthor, P. (2006). Atmospheres: Architectural Environments, Surrounding Objects. 
